\title{
Under a nonadherent state, bone marrow mesenchymal stem cells can be efficiently induced into functional islet-like cell clusters to normalize hyperglycemia in mice: a control study
}

Yihua Zhang ${ }^{*}$ and Zhongying Dou

\begin{abstract}
Introduction: Bone marrow mesenchymal stem cells (BMSCs) possess low immunogenicity and immunosuppression as an allograft, can differentiate into insulin-producing cells (IPCs) by in vitro induction, and may be a valuable cell source to regenerate pancreatic islets. However, the very low differentiation efficiency of BMSCs towards IPCs under adherent induction has thus far hindered the clinical exploitation of these cells. The aim of this study is to explore a new way to efficiently induce BMSCs into IPCs and lay the groundwork for their clinical exploitation.
\end{abstract}

Methods: In comparison with adherent induction, BMSCs of human first-trimester abortus (hfBMSCs) under a nonadherent state were induced towards IPCs in noncoated plastic dishes using a three-stage induction procedure developed by the authors. Induction effects were evaluated by statistics of the cell clustering rate of induced cells, and ultrastructural observation, dithizone staining, quantitative polymerase chain reaction and immunofluorescence assay, insulin and c-peptide release under glucose stimulus of cell clusters, as well as transplantation test of the cell clusters in diabetic model mice.

Results: With $(6.175 \pm 0.263) \times 10^{5}$ cells in $508.5 \pm 24.5$ cell clusters, $(3.303 \pm 0.331) \times 10^{5}$ single cells and $(9.478 \pm 0.208) \times 10^{5}$ total cell count on average, $65.08 \pm 2.98 \%$ hfBMSCs differentiated into pancreatic islet-like cell clusters after nonadherent induction. With $(3.993 \pm 0.344) \times 10^{5}$ cells in $332.3 \pm 41.6$ cell clusters, $(5.437 \pm 0.434) \times 10^{5}$ single cells and $(9.430 \pm 0.340) \times 10^{5}$ total cell count on average, $42.37 \pm 3.70 \%$ hfBMSCs differentiated into pancreatic islet-like cell clusters after adherent induction $(P<0.01, n=10)$. The former is significantly higher than the latter. Calculated according to the cell clustering rate and IPC percentage in the cell clusters, $29.80 \pm 3.95 \% \mathrm{hfBMSCs}$ differentiated into IPCs after nonadherent induction and 18.40 $2.08 \%$ hfBMSCs differentiated into IPCs after adherent induction $(P<0.01, n=10)$, the former significantly higher than the latter. The cell clusters expressed a broad gene profile related to pancreatic islet cells, released insulin and c-peptide in a glucose concentration-dependent manner, and normalized hyperglycemia of streptozocin-induced mice for at least 80 days following xenograft. Blood glucose of grafted mice rose again after their graft removed. A series of examination of the grafts showed that transplanted cells produced human insulin in recipients.

Conclusions: Our studies demonstrate that nonadherent induction can greatly promote BMSCs to form pancreatic islet-like cell clusters, thereby improving the differentiation efficiency of BMSCs towards IPCs.

\footnotetext{
*Correspondence: zyh19620207@163.com

Shaanxi Branch of National Stem Cell Engineering and Technology Centre,

College of Veterinary Medicine, Northwest A \& F University, Yangling, Shaanxi

712100, China
}

\section{Biomed Central}

(c) 2014 Zhang and Dou; licensee BioMed Central Ltd. This is an Open Access article distributed under the terms of the Creative Commons Attribution License (http://creativecommons.org/licenses/by/2.0), which permits unrestricted use, distribution, and reproduction in any medium, provided the original work is properly credited. The Creative Commons Public Domain Dedication waiver (http://creativecommons.org/publicdomain/zero/1.0/) applies to the data made available in this article, unless otherwise stated. 


\section{Introduction}

Type 1 diabetes (insulin-dependent diabetes mellitus), with an annual net rise of about $3 \%$ in incidence [1], results from the autoimmune lesion of pancreatic beta-cells. Insulindependent diabetes mellitus has been successfully treated by transplantation with pancreatic islets of Langerhans [2,3], but further application of this therapy is limited by the lack of Langerhans donors and immunological rejection. Fortunately, bone marrow mesenchymal stem cells (BMSCs) not only differentiate into multiple mesodermal and nonmesodermal cell lineages including insulin-producing cells (IPCs) [4-11], but also possess low immunogenicity [12] and immunosuppression by modulating the immune function of the major cell populations involved in alloantigen recognition and elimination [13-21]. These unique biological properties make BMSCs a promising source for cell replacement of kinds of tissue necrosis and function cell exhaustion, especially insulin-dependent diabetes mellitus.

Under adherent induction, however, BMSCs are not effective to form cell clusters, leading to the very low differentiation efficiency of BMSCs towards IPCs. We hypothesized that nonadherent induction favors the formation of cell clusters, thereby improving the differentiation efficiency of BMSCs towards IPCs. To verify this hypothesis, we induced BMSCs of human firsttrimester abortus (hfBMSCs) under a nonadherent state to efficiently differentiate into functional islet-like cell clusters, which corrected hyperglycemia in model mice following xenograft. This study provides a new way to induce BMSCs in vitro into pancreatic islet-like cells to treat insulin-dependent diabetes mellitus.

\section{Methods}

\section{Preparation of hfBMSCs}

Under permission of the patients, a local hospital and the Ethics Committee of Northwest A \& F University, hfBMSCs were isolated from long bones of 2-month-old to 3month-old human abortuses using whole-marrow cell culture and proliferated in $\alpha$-modified Eagle's medium (Gibco, Billings, Montana, USA), 10\% fetal calf serum (Stemcell Technologies Inc., Vancouver, British Columbia, Canada) and $0.1 \mathrm{mmol} / \mathrm{l} \beta$-mercaptoethanol (Sigma Loveland, CO, USA). The cells were identified using flow cytometry (Beckman Coulter Inc., Fullerton, California, USA) and CD29, CD44, CD166, CD11a, CD14 and CD34 fluorescencetagged antibodies (Beckman Coulter Inc.).

\section{In vitro induction of hfBMSCs towards insulin-producing cells}

Passage 6 of the cryopreserved hfBMSCs was thawed, and proliferated to passage 8 in $\alpha$-modified Eagle's medium, $20 \%$ fetal calf serum, and $0.1 \mathrm{mmol} / \mathrm{l} \beta$-mercaptoethanol. Passage 8 of hfBMSCs underwent acclimation in Dulbecco's modified Eagle's medium (DMEM)-high glucose (containing $25 \mathrm{mmol} / \mathrm{l}$ glucose; HyClone, Logan, Utah, USA), $10 \%$ fetal calf serum, and $0.1 \mathrm{mmol} / \mathrm{l} \beta$ mercaptoethanol, were digested, were transferred into noncoated plastic dishes (in which hfBMSCs are nonadherent), and were induced using a three-stage induction procedure developed by the authors. This procedure was respectively performed 10 times using hfBMSCs from different abortus $(n=10)$, with nine replications each and each replication covering one dish containing more than $1 \times 10^{6}$ hfBMSCs, as the nonadherent induction group. The same hfBMSCs were transferred into lysine-coated plastic dishes (in which hfBMSCs are adherent) and induced using the same procedure $(n=10)$ as the adherent induction group.

In stage one of the procedure, the hfBMSCs were cultured for 6 days to develop nestin-positive cells with DMEM-high glucose plus $10 \mathrm{ng} / \mathrm{ml}$ basic fibroblast growth factor (Invitrogen, Carlsbad, California, USA), $10 \mathrm{ng} / \mathrm{ml}$ epidermal growth factor (EGF; Chemicon, California, USA), 2\% B27 supplement (Stemcell Technologies Inc.), $0.5 \%$ bovine serum albumin (BSA; Invitrogen), and $0.1 \mathrm{mmol} / \mathrm{l} \beta$-mercaptoethanol, with medium changes every 2 days. Stage two differentiated nestin-positive cells into IPCs via a 6-day induction with DMEM-high glucose plus $10 \mathrm{ng} / \mathrm{ml}$ EGF, $20 \mathrm{ng} / \mathrm{ml}$ Activin A (Sigma), $10 \mathrm{mmol} / \mathrm{l}$ nicotinamide (Sigma), 2\% B27, 0.5\% BSA, and $0.1 \mathrm{mmol} / \mathrm{l} \beta$-mercaptoethanol, with medium changes every 2 days. Stage three was the maturation of the expected IPCs via a 4-day culture with DMEM-low glucose (containing $5.6 \mathrm{mmol} / \mathrm{l}$ glucose; Gibco) plus 10 ng/ml EGF, 10 nmol/l exendin-4 (Sigma), $10 \mathrm{ng} / \mathrm{ml}$ betacellulin (Sigma), 2\% B27, 0.5\% BSA, and $0.1 \mathrm{mmol} / \mathrm{l} \beta$-mercaptoethanol, with medium changes every 2 days.

\section{Statistics of the cell clustering rate}

After each time induction, one dish was picked out randomly, cell clusters and single cells in the dishes were collected respectively, and cells from the cell clusters and the single cells were counted respectively. The cell clustering rate was calculated according to the cell number in the cell clusters divided by the summation of the single cells and cells in the cell clusters $(n=10)$, and the average cell number of each cell cluster was calculated according to the cell number in the cell clusters divided by the cell cluster number $(n=10)$.

\section{Ultrastructural observation of endocrine cells in cell clusters}

After each time induction, one dish was randomly picked from the nonadherent induction group and the adherent induction group $(n=10)$. The cell clusters were centrifuged for 10 minutes, fixed in $0.1 \%$ glutaraldehyde/ 
$2 \%$ formaldehyde in $0.1 \mathrm{~mol} / \mathrm{l}$ cacodylate buffer, transferred to $0.1 \mathrm{~mol} / \mathrm{l}$ cacodylate buffer, and embedded. Ultrathin sections were prepared, observed and photographed under a transmission electron microscope (H-7650; Hitachi, Japan). Fetal pancreatic islets, newly isolated from the pancreas of human abortus at the age of 20 weeks according to Kover and Moore [22], were used as the positive control.

\section{Dithizone staining}

After each time induction, one dish was randomly picked from the nonadherent induction group and the adherent induction group and cell clusters were collected respectively $(n=10)$. The cell clusters, non-induced hfBMSCs (as non-induction control), and some fetal pancreatic islets (as positive control) were stained for 15 minutes with a freshly prepared dithizone (Sigma) working solution at $37^{\circ} \mathrm{C}$, washed three times with phosphate-buffered saline (PBS), observed and photographed under an optical microscope.
Fluorescent quantitative reverse transcriptase-polymerase chain reaction assay

To clarify the in vitro expression levels of pdx1, ngn3, pax4, neuroD1, nkx2.2, nkx6.1, PCSK1, insulin, glucagon, SST, and PP genes in induced cells, fluorescent quantitative reverse transcriptase-polymerase chain reaction was performed. Total RNA of cell clusters from each time induction in the nonadherent induction group and the adherent induction group, fetal pancreatic islets as positive control and non-induced hfBMSCs as noninduction control were extracted with $\mathrm{TRlzol}^{\circ}$ Reagent (Invitrogen) and each was reverse-transcribed into cDNA with the PrimerScript RT reagent kit (TaKaRa, Tokyo, Japan) according to the manufacturer's manual $(n=10)$. The forward and reverse primers and the fluorescent quantitative polymerase chain reaction details for the marker genes in this study are presented in Table 1.

\section{Immunofluorescence assay}

To test the expression of nestin, insulin and c-peptide during the induction, cell clusters were sampled individually

Table 1 Human gene-specific primers and quantitative polymerase chain reaction conditions

\begin{tabular}{|c|c|c|c|c|}
\hline Gene & Primer sequence $\left(5^{\prime}\right.$ to $\left.3^{\prime}\right)$ & Size of PCR product (base pairs) & Annealing temperature $\left({ }^{\circ} \mathrm{C}\right)$ & Cycle number \\
\hline \multirow[t]{2}{*}{ 18SrRNA } & Forward: CGGCTACCACATCCAAGGAA & 187 & 62 & 40 \\
\hline & Reverse: GCTGGAATTACCGCGGCT & & & \\
\hline \multirow[t]{2}{*}{$P d \times 1$} & Forward: TTCCGGAAGAAAAAGAGCCA & 129 & 62 & 40 \\
\hline & Reverse: AAACAGGTCCCAAGGTGGAGT & & & \\
\hline \multirow[t]{2}{*}{ Ngn3 } & Forward: CGCAATCGAATGCACAACCT & 135 & 62 & 40 \\
\hline & Reverse: TTGAGTCAGCGCCCAGATGTA & & & \\
\hline \multirow[t]{2}{*}{ Pax4 } & Forward: ATTCAGTGGCCCGTGGAAA & 102 & 62 & 40 \\
\hline & Reverse: TCTCTTGCCGACGCCATTT & & & \\
\hline \multirow[t]{2}{*}{ NeuroD1 } & Forward: TCTITCAAACACGAACCGTCC & 103 & 62 & 40 \\
\hline & Reverse: AGATTGATCCGTGGCTITGG & & & \\
\hline \multirow[t]{2}{*}{$\mathrm{Nk} \times 2.2$} & Forward: GCCACGAATTGACCAAGTGAA & 103 & 62 & 40 \\
\hline & Reverse: ATGTCCTTGACCGAAAACCCC & & & \\
\hline \multirow[t]{2}{*}{ Nkx6.1 } & Forward: ACACGAGACCCACTITTTCCG & 102 & 62 & 40 \\
\hline & Reverse: AATAGGCCAAACGAGCCCTCT & & & \\
\hline \multirow[t]{2}{*}{ PCSK1 } & Forward: TCCTCTITTGCGCTTGGTGT & 139 & 62 & 40 \\
\hline & Reverse: TGACCCAAAAGGTCATAGCCC & & & \\
\hline \multirow[t]{2}{*}{ Insulin } & Forward: GCGTGGCATTGTGGAACAA & 123 & 62 & 40 \\
\hline & Reverse: CCATCTCTCTCGGTGCAGGA & & & \\
\hline \multirow[t]{2}{*}{ Glucagon } & Forward: ACATTGCCAAACGTCACGATG & 103 & 62 & 40 \\
\hline & Reverse: GCAATGAATTCCTTGGCAGCT & & & \\
\hline \multirow[t]{2}{*}{ SST } & Forward: GAAGCAGGAACTGGCCAAGTA & 118 & 62 & 40 \\
\hline & Reverse: CCTCATTTCATCCTGCTCAGC & & & \\
\hline \multirow[t]{2}{*}{ PP } & Forward: ACAATGCCACACCAGAGCAGA & 110 & 62 & 40 \\
\hline & Reverse: GGCCAGCGTGTCCTCTITG & & & \\
\hline
\end{tabular}


following each induction stage, respectively fixed in $4 \%$ paraformaldehyde for 20 to 30 minutes, triple-washed with PBS, and stained with mouse antibodies against human nestin (Abcam, Cambridge, Massachusetts, UK) and insulin (Invitrogen), and rabbit anti-human c-peptide antibody (Abcam), and then with secondary fluorescent antibodies including fluorescein isothiocyanate-conjugated donkey anti-mouse IgG and Alexa Flour 594-conjugated goat anti-rabbit IgG (Invitrogen). To investigate the expression rate of IPCs and other endocrine cells in cell clusters, the cell clusters from each time induction were respectively digested, subcultured for 24 hours in a lysinecoated 24-well plate before fixation, stained with mouse anti-human insulin and glucagon, rabbit anti-human SST and PP antibodies (Invitrogen), and the relevant IgGs conjugated with fluorescence. Ten nonoverlapping visual fields were randomly chosen from each staining sample to count stained and nonstained cells under microscopy, and they were photographed using an inverted microscope. The proportion of cells immunoreactive to particular antigens was quantified according to the stained cell number divided by the summation number of stained cells and nonstained cells $(n=10)$.

\section{In vitro insulin and c-peptide release in response to increasing glucose concentrations}

After each time induction, cell clusters were sampled from the nonadherent induction group and the adherent induction group respectively, transferred into 12-well culture plates containing a lysine coating for cells to attach, 100 clusters per well, and were precultured in DMEM-low glucose, $10 \mathrm{ng} / \mathrm{ml} \mathrm{EGF,} \mathrm{2 \%} \mathrm{B27,} \mathrm{0.5 \%} \mathrm{BSA,}$ and $0.1 \mathrm{mmol} / \mathrm{l} \beta$-mercaptoethanol for 24 hours, washed three times with $\mathrm{PBS}$, and stimulated with $1 \mathrm{ml}$ of either 5,10 , or $25 \mathrm{mmol} / \mathrm{l}$ glucose in PBS containing 1\% BSA $(n=10)$. In parallel, 100 fetal pancreatic islets (positive control) and $1.2 \times 10^{5}$ hfBMSCs at passage 8 (equivalent to 100 cell clusters, non-induction control) were treated in the same way with all three glucose levels. The supernatants from all treatments were collected after 30 minutes of stimulation, and insulin and c-peptide were measured via radioimmunoassay with the human insulin-specific RIA kit and the human c-peptide RIA kit (LINCO Research Inc., St. Charles, MO, USA) and a liquid scintillation counter (LS6000; Beckman Co., USA).

\section{Preparation of type 1 diabetic model mice}

Approved by the Institutional Animal Care and Use Committee of Northwest A \& F University, a total of 35 adult male nude mice (BALB/c nu/nu), provided by the Experiment Animal Centre of the Fourth Military Medical University (Xi'an, China), each with normal blood glucose levels, were administered daily intraperitoneal injections of $50 \mathrm{mg} / \mathrm{kg}$ streptozocin (STZ; Sigma) for 5 consecutive days. At 72 hours after the last STZ injection, fasting blood glucose levels were determined using a standard blood glucose meter (Sure Step ${ }^{\mathrm{TM}}$ Plus; LifeScan Inc., Milpitas, CA, USA) once a day for 3 consecutive days. If the three fasting blood glucose levels were all higher than $18 \mathrm{mmol} / \mathrm{l}$, the mouse was used as a diabetic model animal for our experiments.

\section{Transplantation of CM-Dil-labeled cell clusters to treat diabetic mice}

Cell clusters from the nonadherent induction group and the adherent induction group, and also non-induced hfBMSCs, were incubated individually in a working solution of Cell Tracker-CM-DiI (Molecular Probes, Invitrogen Carlsbad, California, USA) for 5 minutes at $37^{\circ} \mathrm{C}$ and for another 15 minutes at $4^{\circ} \mathrm{C}$ according to the manufacturer's instructions, followed by washing with PBS, and were checked under a fluorescence microscope. The 600 CM-DiI-labeled cell clusters from the nonadherent induction (about $7.2 \times 10^{5}$ cells) were transplanted into the right-side testis of 10 diabetic model mice each as the nonadherent induction group $(n=10)$. The 600 CM-DiI-labeled cell clusters from the adherent induction were transplanted into the right-side testis of another 10 diabetic model mice each as the adherent induction group $(n=10)$. CM-DiI-labeled but non-induced $7.2 \times 10^{5}$ hfBMSCs were transplanted into the right-side testis of another six diabetic model mice each as the noninduction control group $(n=6)$. Blood glucose levels of animals in each of the three treatments were measured once every 4 days using a standard blood glucose meter and the body weight was measured once every 8 days using an electronic balance (Mettler-Toledo Inc., Columbus, $\mathrm{OH}$, USA).

To examine the effects of graft removal on the blood glucose fluctuation and the survival situation of the recipients, and the in situ insulin production of the xenografts, three mice were randomly selected from each animal group and their right testes removed 28 days post transplantation following similar blood glucose and body weight measurements. Histological sections of all testicular grafts were dewaxed and stained with mouse monoclonal antibodies against human insulin and then with fluorescein isothiocyanate-conjugated donkey antimouse IgG, and were examined using a fluoroscope.

To evaluate the glucose clearance effects of the transplanted islet-like cell clusters, the intraperitoneal glucose tolerance test was performed on five mice in each of the nonadherent induction group and the adherent induction group after 12 days of glucose level normalization following the transplantation and on five nondiabetic mice (as normal control). Each mouse was intraperitoneally injected with glucose at $2 \mathrm{mg} / \mathrm{g}$ body weight under 
fasting conditions and tested for blood glucose at 0,30 , $60,90,120$, and 150 minutes thereafter [23].

\section{Data processing}

Data are treated for significance with Student's $t$ test or SPSS 12.0 simplified Chinese version one-way analysis of variance where applicable. In all cases, all values are presented as mean \pm standard deviation and $P<0.05$ was considered significant.

\section{Results}

\section{Preparation of hfBMSCs}

The whole-marrow cell culture resulted in spindle cell adherence (Figure 1A). Many spindle cells then clonally grew and spread at the bottom of a culture dish within the 12th day (Figure 1B). Several hundred dishes of sixth-passage cells (about $10^{6}$ cells in every dish) were obtained upon continuously passaging culture and were cryopreserved in liquid nitrogen. Flow cytometric analysis showed that passage 6 of the isolated cells strongly expressed the surface markers of mesenchymal stem cells, such as CD29, CD44 and CD166, but almost no markers of Hematopoietic Stem Cells, such as CD11a, CD14 and CD34 (Figure 1C).

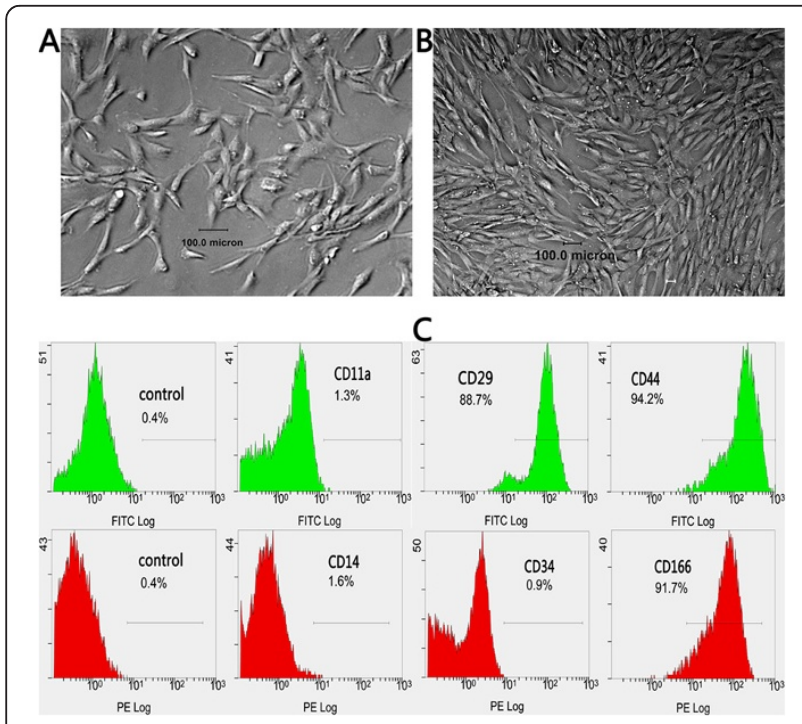

Figure 1 Isolation and identification of bone marrow mesenchymal stem cells of human first-trimester abortus. Adhered spindle cells appeared in culture of whole bone marrow (A) and they clonally grew and spread at the bottom of a culture dish within the 12th day (B). Flow cytometric analysis showed that passage 6 of the isolated cells strongly expressed the surface markers of mesenchymal stem cells, such as CD29, CD44 and CD166, but almost no markers of Hematopoietic Stem Cells, such as CD11a, CD14 and CD34 (C). FITC, fluorescein isothiocyanate; PE, phycoerythrin.

\section{Differentiation of hfBMSCs into islet-like cell clusters}

In the first-stage induction, most hfBMSCs in the nonadherent induction group congregated on the dish bottoms to gradually form many irregular cell clusters (Figure 2A), whereas a few cells died and floated on the medium surface. Comparatively, less than one-half of the hfBMSCs in the adherent induction group congregated into irregular cell clusters adhering to the dish bottom (Figure 2E). In the second-stage induction, the cell clusters in the nonadherent induction group gradually became compact (Figure 2B), whereas the cell clusters in the adherent induction group became hemispherical and firmly adhered to the dish bottom (Figure 2F). In the third-stage induction, the cell clusters in the nonadherent induction group gradually became spherical with blurred boundaries between adjacent cells on the surface, similar to the morphology of the islets of Langerhans, whereas some of the nonclustered cells adhered to the dish bottom and became similar to hfBMSCs in shape (Figure 2C,D). Comparatively, the cell clusters in the adherent induction group gradually uplifted but still adhered to the dish bottom, with blurred boundaries between adjacent cells on the surface (Figure 2G,H).

With $(6.175 \pm 0.263) \times 10^{5}$ cells in $508.5 \pm 24.5$ cell clusters, $(3.303 \pm 0.331) \times 10^{5}$ single cells, $(9.478 \pm 0.208) \times 10^{5}$ total cell count and 1,215.07 \pm 35.38 cells in each cluster on average, $65.08 \pm 2.98 \%$ hfBMSCs differentiated into pancreatic islet-like cell clusters in the nonadherent induction group $(n=10)$. With $(3.993 \pm 0.344) \times 10^{5}$ cells in $332.3 \pm 41.6$ cell clusters, $(5.437 \pm 0.434) \times 10^{5}$ single cells, $(9.430 \pm 0.340) \times 10^{5}$ total cell count and 1,199.36 \pm 63.41 cells in each cluster on average, $42.37 \pm 3.70 \%$ hfBMSCs differentiated into pancreatic islet-like cell clusters in the adherent induction group $(n=10)$. The former is significantly higher than the latter $(P<0.01, n=10)$. However, the total cell count and average cell number of each cell cluster are not significantly different between the nonadherent induction group and the adherent induction group $(P>0.05, n=10)$. Under transmission electron microscopy, a large number of endocrine cells (Figure 2I) and secretion granules in cytoplasma were observed in the sections of islet-like cell clusters in the nonadherent induction group (Figure 2J) and the adherent induction group (Figure $2 \mathrm{~K}$ ), which were histologically similar to those in fetal pancreatic islets as a positive control (Figure 2L).

\section{Dithizone staining}

Dithizone is a zinc-chelating agent used to selectively stain pancreatic beta-cells crimson red. The insulin production of the islet-like cell clusters was verified by positive dithizone staining in the nonadherent induction group (Figure 3A.a) and the adherent induction group (Figure 3A.b), similar to staining behavior of fetal pancreatic 


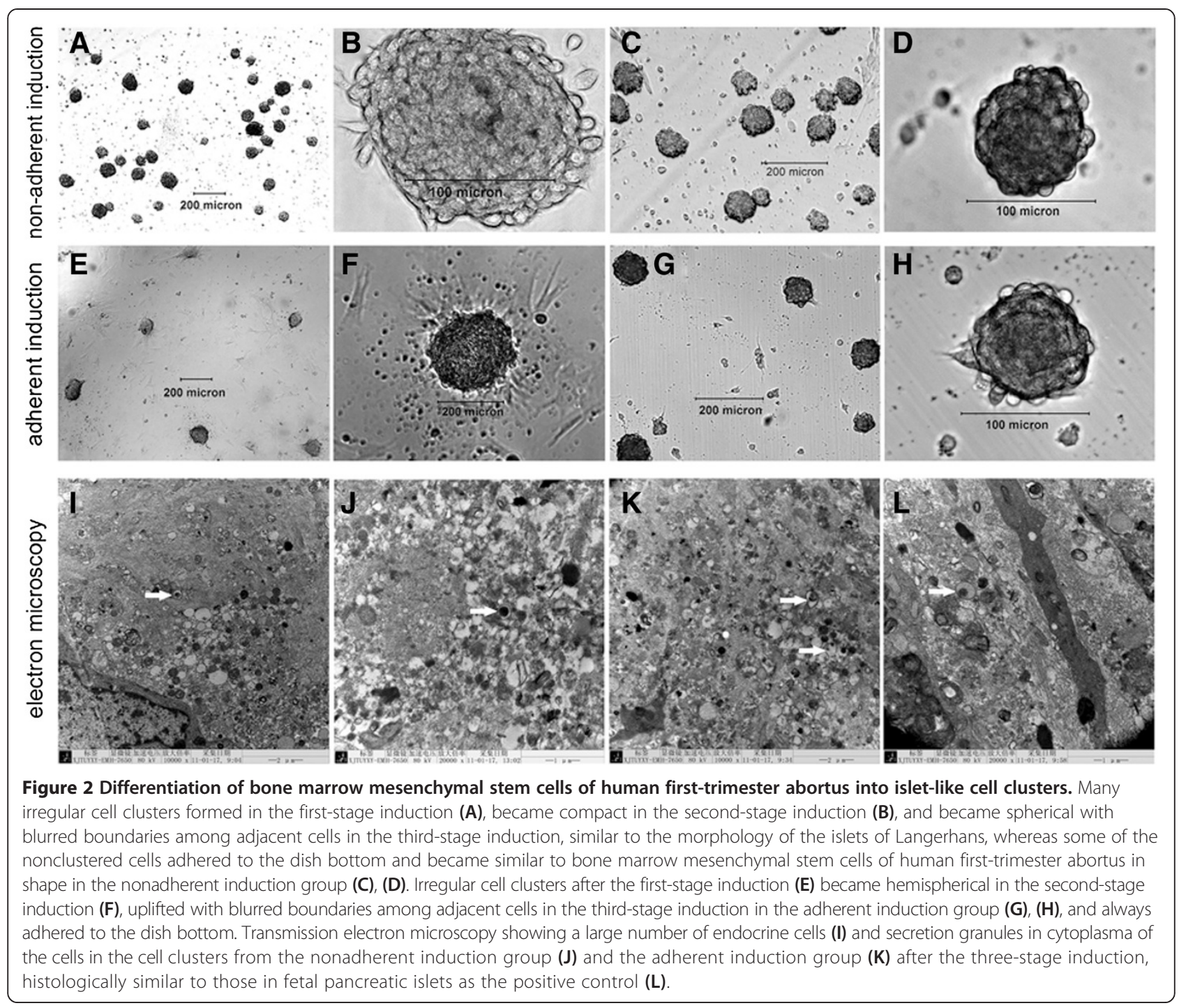

islets (Figure 3A.c), and non-induced hfBMSCs were negative for dithizone (Figure 3A.d).

\section{Fluorescent quantitative reverse transcriptase-polymerase chain reaction}

Fluorescent quantitative reverse transcriptase-polymerase chain reaction (Figure $3 \mathrm{~B}$ ) showed that the islet-like cell clusters in the nonadherent induction group and the adherent induction group all expressed pdx1, ngn3, pax4, neuroD1, nkx2.2, nkx6.1, PCSK1, insulin, glucagon, SST and PP, similar to the expression profile of fetal pancreatic islets. However, the islet-like cell clusters in the nonadherent induction group and the adherent induction group expressed significantly more Ngn3 and Pax4, and significantly less insulin, glucagon, SST and PP than fetal pancreatic islets (all $P<0.01, n=10$ ), indicating that the cell clusters from hfBMSCs induced in vitro were not mature enough. The expression of the genes was similar between the nonadherent induction group and the adherent induction group.

\section{Immunofluorescence assay}

The immunofluorescence assay indicated that the islet-like cell clusters from the nonadherent induction group and the adherent induction group all expressed nestin, insulin and c-peptide (Figure 4); that is, nestin was more expressed after the first-stage induction in the nonadherent induction group (Figure 4A,B,C) and the adherent induction group (Figure 4D,E,F), and insulin and c-peptide more expressed after the third-stage induction in the nonadherent induction group (Figure 4G,H,I,J) and the adherent induction group (Figure $4 \mathrm{~K}, \mathrm{~L}, \mathrm{M}, \mathrm{N}$ ) but did not express after the first-stage induction. In contrast, non-induced hfBMSCs did not express insulin and c-peptide (Figure 4O,P,Q,R). The single cells from the digestion of islet-like cell clusters following the three-stage induction adhered during 

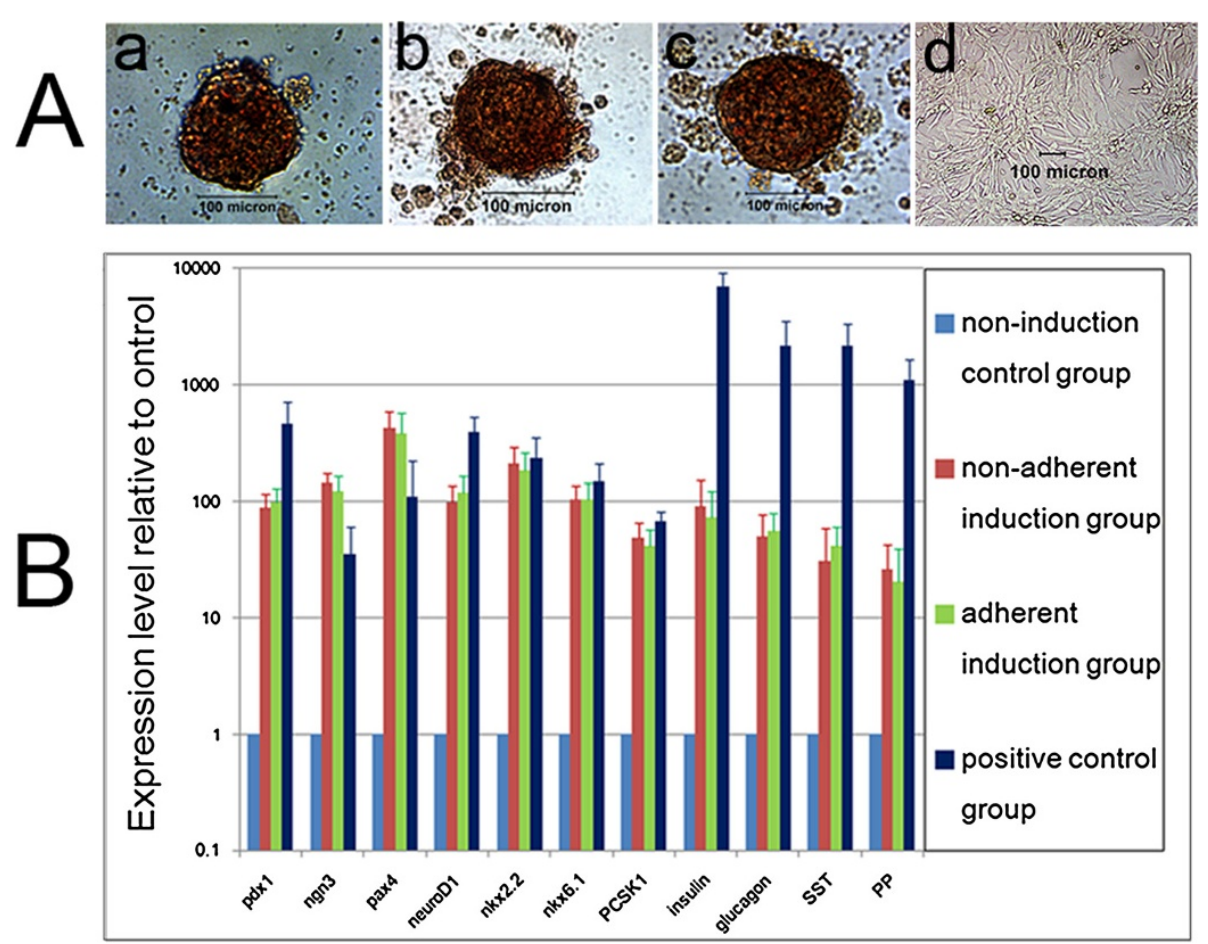

Figure 3 Dithizone staining and quantitative polymerase chain reaction analysis of islet-like cell clusters from bone marrow mesenchymal stem cells of human first-trimester abortus. (A) Islet-like cell clusters were positive for dithizone staining in the nonadherent induction group (a) and the adherent induction group (b), similar to those of fetal pancreatic islets (c), whereas non-induced bone marrow mesenchymal stem cells of human first-trimester abortus were negative for dithizone (d). (B) Expression levels of Pdx1, Ngn3, Pax4, NeuroD1, Nkx2.2, Nkx6.1, PCSK1, insulin, glucagon, SST and PP genes in fluorescent quantitative reverse transcriptase-polymerase chain reaction test. The islet-like cell clusters expressed significantly more Ngn3 and Pax4, and significantly less insulin, glucagon, SST and PP than fetal pancreatic islets $(P<0.01, n=10)$. The expressions of all the genes were not different between the nonadherent induction group and the adherent induction group $(P>0.05, n=10)$.

24 hours of subculture and then were fixed and stained for insulin, glucagon, SST and PP (Figure 5). The positive cell percentages for insulin, glucagon, SST and PP were successively $45.79 \pm 5.87 \%, 7.12 \pm 2.15 \%, 6.33 \pm$ $2.86 \%$ and $4.54 \pm 1.54 \%$ in the nonadherent induction group $(n=10)$, and were $43.42 \pm 6.81 \%, 8.35 \pm 2.72 \%$, $5.38 \pm 2.13 \%$ and $3.66 \pm 1.32 \%$ in the adherent induction group $(n=10)$ respectively. The percentages of each kind of positive cells were not different between the nonadherent induction group and the adherent induction group (all $P>0.05, n=10$ ). In addition, the differentiation rate of hfBMSCs towards IPCs (the cell clustering rate $\times$ the percentage of IPCs in islet-like cell clusters) was calculated as $29.80 \pm 3.95 \%$ in the nonadherent induction group, which was significantly higher than the differentiation rate $(18.40 \pm 2.08 \%)$ in the adherent induction group $(P<0.01, n=10)$.

\section{In vitro insulin and C-peptide release in response to a glucose challenge}

The results of glucose challenge (Figure 6) indicated that the islet-like cell clusters from the nonadherent induction group and the adherent induction group all released insulin and c-peptide at significantly higher levels than those of the non-induction control group (all $P<0.01, n=10$ ). The results also indicated that the insulin and c-peptide releases of the islet-like cell clusters in response to glucose challenge occurred in a concentration-dependent manner because there was significant difference of each release among different glucose levels (all $P<0.01, n=10$ ). Finally, the release of insulin and c-peptide from the islet-like cell clusters in the nonadherent induction group and the adherent induction group was much less than those of fetal pancreatic islets (all $P<0.01, n=10$ ), and they were no different between the nonadherent induction group and the adherent induction group (all $P>0.05, n=10$ ).

\section{Effects of islet-like cell clusters to treat diabetic mice} After STZ injection, 26 of 35 (74\%) of the nude mice became eligible diabetic models. Following transplantation with islet-like cell clusters, in the nonadherent induction group the blood glucose levels of 10 diabetic mice all sank to normal levels within 12 days, but the blood glucose levels of three mice whose testes was removed 

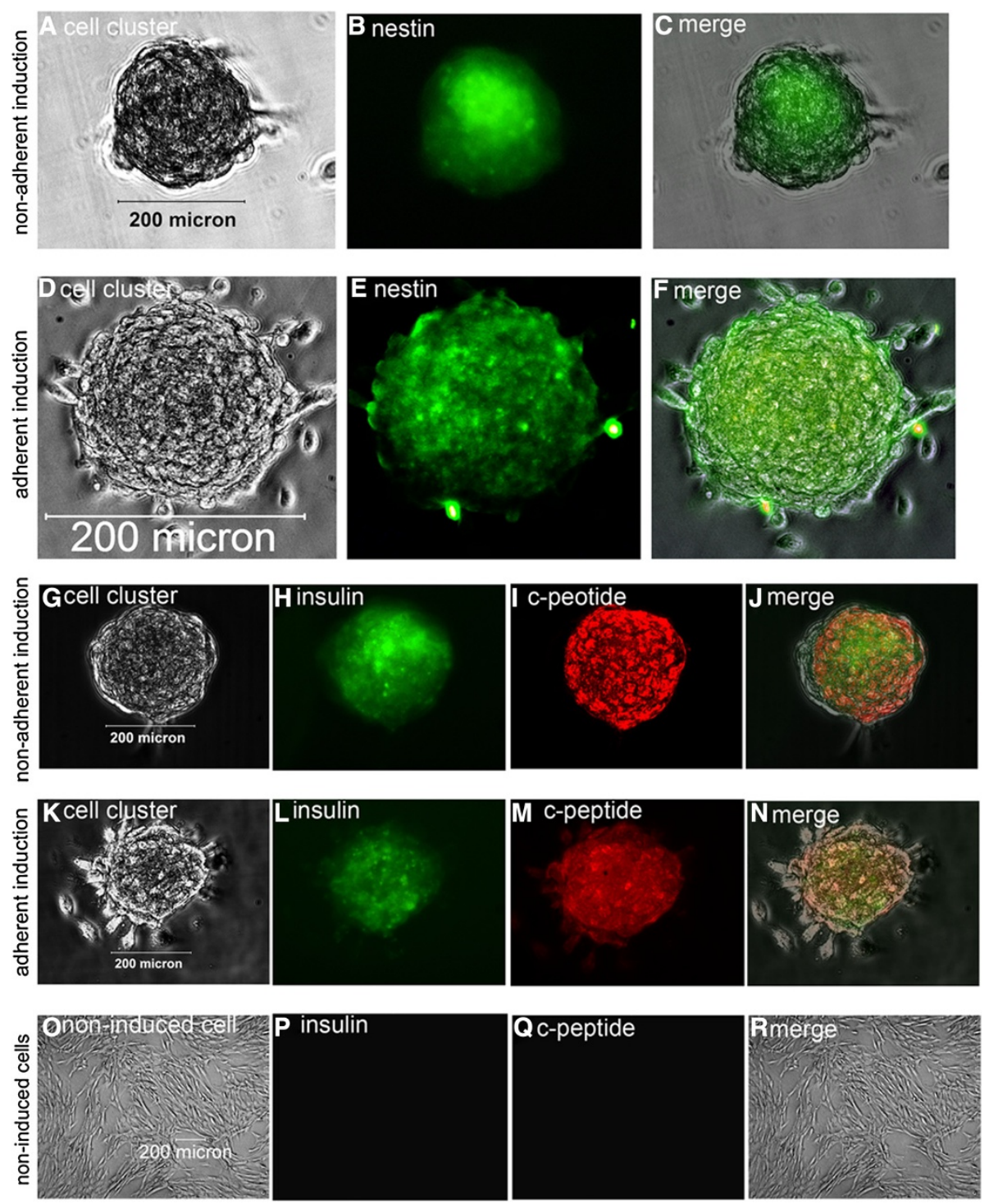

Figure 4 Immunofluorescence assay of whole islet-like cell clusters. The strongest expression of nestin is in islet-like cell clusters after the first-stage induction in the nonadherent induction group (A), (B), (C) and the adherent induction group (D), (E), (F). The strongest expression of insulin and c-peptide is in islet-like cell clusters after the third-stage induction in the nonadherent induction group (G), (H), (I), (J) and the adherent induction group (K), (L), (M), (N). Non-induced bone marrow mesenchymal stem cells of human first-trimester abortus were negative for insulin and c-peptide (O), (P), (Q), (R).

28 days after transplantation rose again and they all died within another 45 days; the remaining seven mice without the removal of xenograft maintained normal blood glucose values for at least 80 days (Figure 7A) and gained body weight slightly (Figure 7B). The transplantation effects in the adherent induction group were similar to those in the nonadherent induction group. In the non-induction control group, six diabetic mice maintained high blood glucose levels $(>18 \mathrm{mmol} / \mathrm{l})$ after hfBMSC transplantation, lost their body weight continuously and died within 45 days after the transplantation, and so did the three mice with removal of their testes 28 days post transplantation.

The results of the intraperitoneal glucose tolerance test (Figure 7C) indicated that the islet-like cell clusters from the nonadherent induction group and the adherent induction group were functional, and they were indeed responsive to a glucose challenge in vivo, but were not as effective as native pancreatic beta-cells in terms of restoring normoglycemia. The cells' effects on the restoration of normoglycemia were similar between the nonadherent induction group and the adherent induction group. 

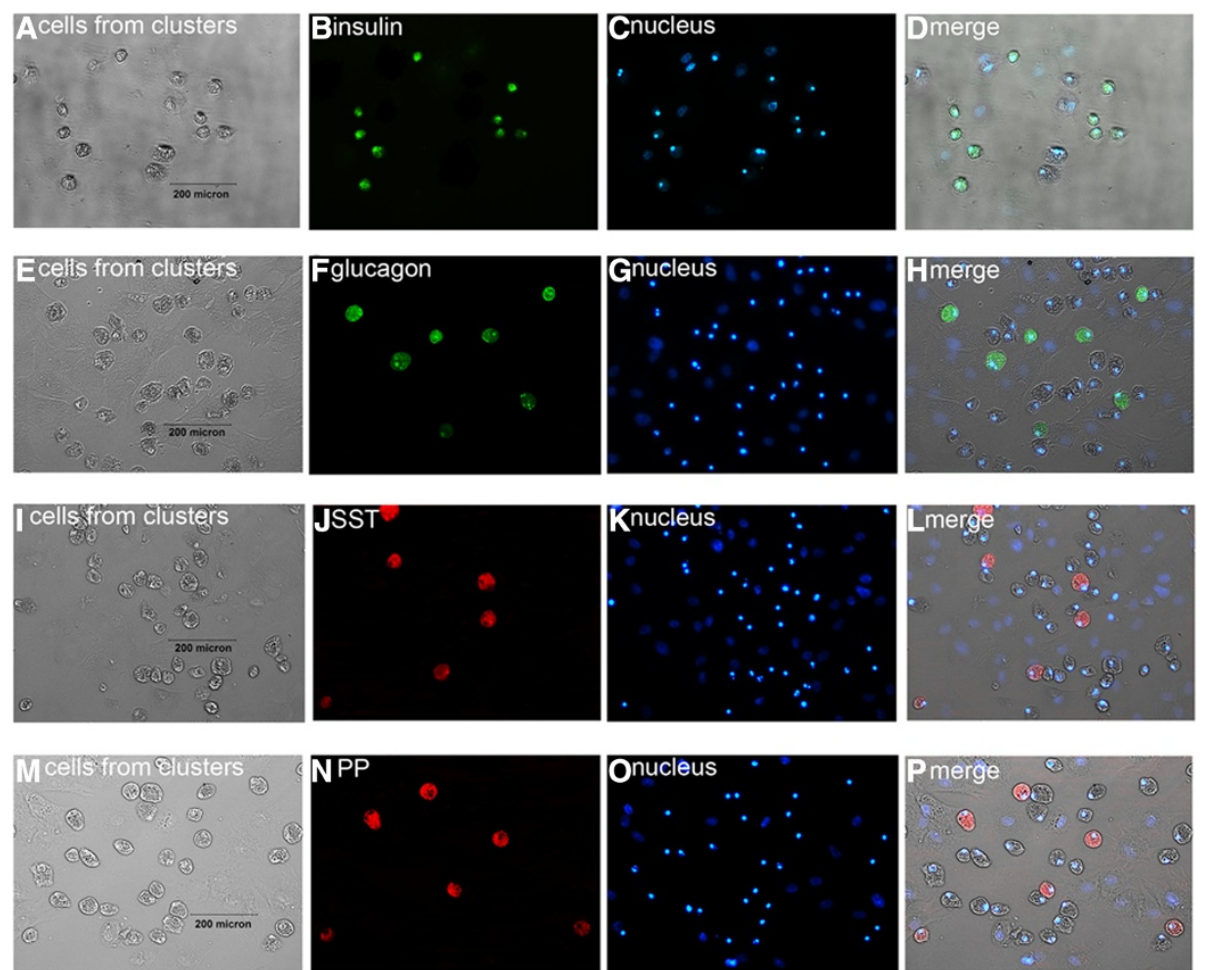

Figure 5 Immunofluorescence assay of single cells from islet-like cell clusters. On enzymatic dispersion and reculture in lysine-coated plastic dishes, the single cells from islet-like cell clusters adhered and expressed insulin (A), (B), (C), (D), glucagon (E), (F), (G), (H), SST (I), (J), (K), (L) and PP (M), (N), (O), (P) respectively.

Direct check of dewaxed testis sections (Figure 8A,E,I, gray-scale image) with red fluoroscope showed that the CM-DiI-labeled cells mainly distributed in the interstitial tissue between seminiferous tubules in the graft (Figure 8B,F,). The immunofluorescent examination of the dewaxed sections indicated that the CM-DiI-labeled red cells in interstitial tissue were positive to human insulin in the nonadherent induction group (green, Figure $8 \mathrm{C}$ ) and the adherent induction group (green, Figure 8G) instead of those in the non-induction control group (Figure 8K), displaying that the insulin was produced by the transplanted islet-like cell clusters instead of by non-induced hfBMSCs.

\section{Discussion}

\section{Nonadherent induction strategies and principle}

BMSCs are a type of cells with strong adhesion tendency. Inducing such cells into cell clusters in lysinecoated plastic dishes is difficult. In this study, hfBMSCs in noncoated plastic dishes (under a nonadherent state) were more efficiently induced into functional pancreatic islet-like cell clusters than those in lysine-coated dishes (under an adherent state) using a three-stage induction procedure. The reason for this difference might be that nonadherent induction in noncoated dishes not only facilitated the contact of hfBMSCs with inducers but also provided a good opportunity for the chemotactic movement, aggregation and clustering of hfBMSCs. Cells in cell clusters, affected by surrounding cells via paracrine, easily coordinated each other and differentiated. Chang and colleagues showed that human BMSCs centrifuged into cell pellets more easily differentiated towards IPCs than those under a monolayer [8]. Studies have shown that cell-cell contact between pancreatic beta-cells is important for maintaining their survival and increasing insulin secretion [24]. In the present study, there were IPCs only in the islet-like cell clusters, whereas single cells in adherent growth did not differentiate towards target cells under the same induction according to their shape and immunofluorescence assay (Figure 4), proving that the environment within the cell clusters was able to promote cell differentiation.

Nestin, a marker of neural stem cells, is also expressed by cells located in the epithelium of the pancreatic primordium. Nestin-positive cells generate the cells of the endocrine and exocrine lineages [25,26], and nestinpositive stem cells from mouse embryonic stem cells can be induced into insulin-positive and c-peptide-positive cells [27]. The newest research indicated that nestin plays pivotal roles as an intermediate regulator governing both stemness and differentiation of stem cells in the process of their differentiation into IPCs [28]. In this study, we efficiently induced hfBMSCs first into nestin- 

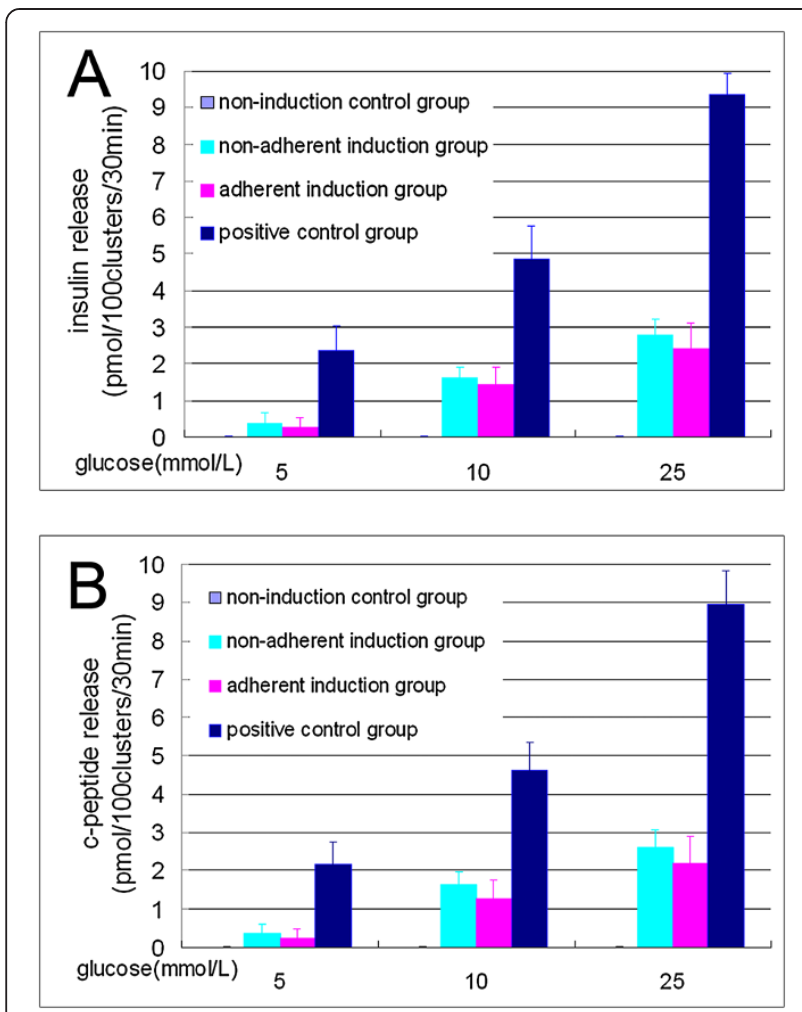

Figure 6 Insulin and C-peptide release by islet-like cell clusters. Radioimmunoassay results show that the release of insulin (A) and c-peptide (B) is significantly different between the nonadherent induction group and the non-induction control group, between the nonadherent induction group and the positive control group, and between the different glucose levels in the nonadherent induction group (all at $P<0.01, n=10$ ), but were not different between the nonadherent induction group and the adherent induction group $(P>0.05, n=10)$.

positive multipotential cell clusters, then into pancreatic islet-like cell clusters and finally into functional islet-like cell clusters (Figures 4 and 6) in noncoated plastic dishes using the three-stage induction procedure. However, the characteristics of nestin-positive cells are still debatable.

\section{Differentiation effects of hfBMSCs after nonadherent induction}

In this study, $65.08 \pm 2.98 \%$ of the hfBMSCs under nonadherent induction differentiated into pancreatic islet-like cell clusters, which is significantly higher than their clustering rate $(42.37 \pm 3.70 \%)$ under adherent induction $(P<0.01, n=10)$. The differentiation rate of hfBMSCs towards IPCs is $29.80 \pm 3.95 \%$ in the nonadherent induction group, which is significantly higher than the differentiation rate $(18.40 \pm 2.08 \%)$ in the adherent induction group $(P<0.01, n=10)$, as well as higher than the differentiation rate (10 to $20 \%)$ of mouse BMSCs in adherence towards IPCs reported by Tang and colleagues [4] and the differentiation rate $(19.8 \%)$ of rat BMSCs in adherence towards
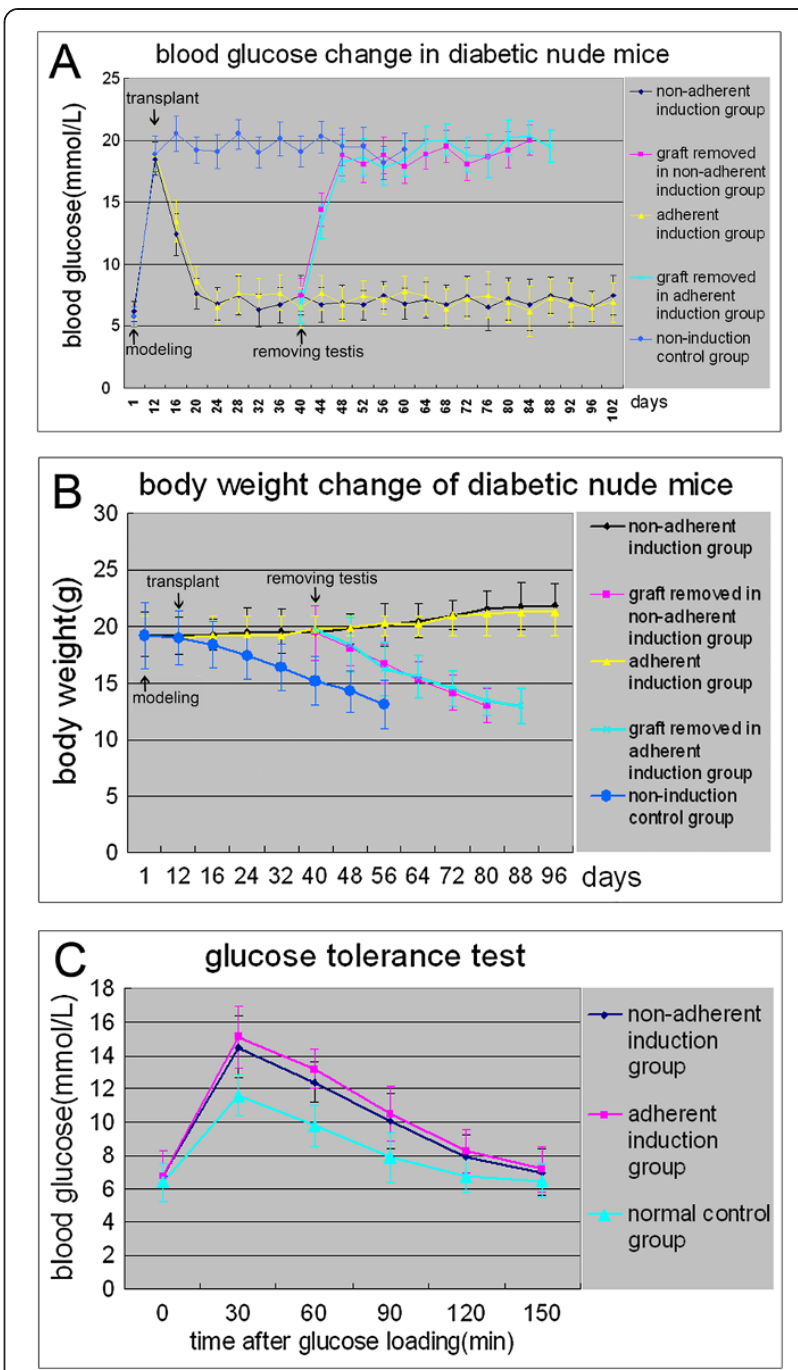

Figure 7 Effects of xenograft with islet-like cell clusters on the recovery of streptozocin-induced diabetic mice. In the nonadherent induction group, the blood glucose levels of 10 diabetic mice fell to normal within 2 weeks following the transplantation, but three of the 10 mice regained hyperglycemia when their xenograft was removed 28 days post transplantation and all died within 45 days after the removal; the remaining seven mice without the removal of xenograft maintained normal levels of blood glucose for at least 80 days (A) and gained body weight slightly (B). The intraperitoneal glucose tolerance test indicated that the islet-like cell clusters had a normal glucose clearance rate after transplantation, but were not as effective as native pancreatic beta-cells $(\mathbf{C})$. The effects of xenograft in the adherent induction group are similar to those in the nonadherent induction group. In the non-induction control group, six diabetic mice maintained high blood glucose levels (>18 mmol/l) after bone marrow mesenchymal stem cell of human first-trimester abortus transplantation, lost their body weight continuously and died within 45 days after the transplantation, and so did the mice with removal of their testes 28 days post transplantation. 


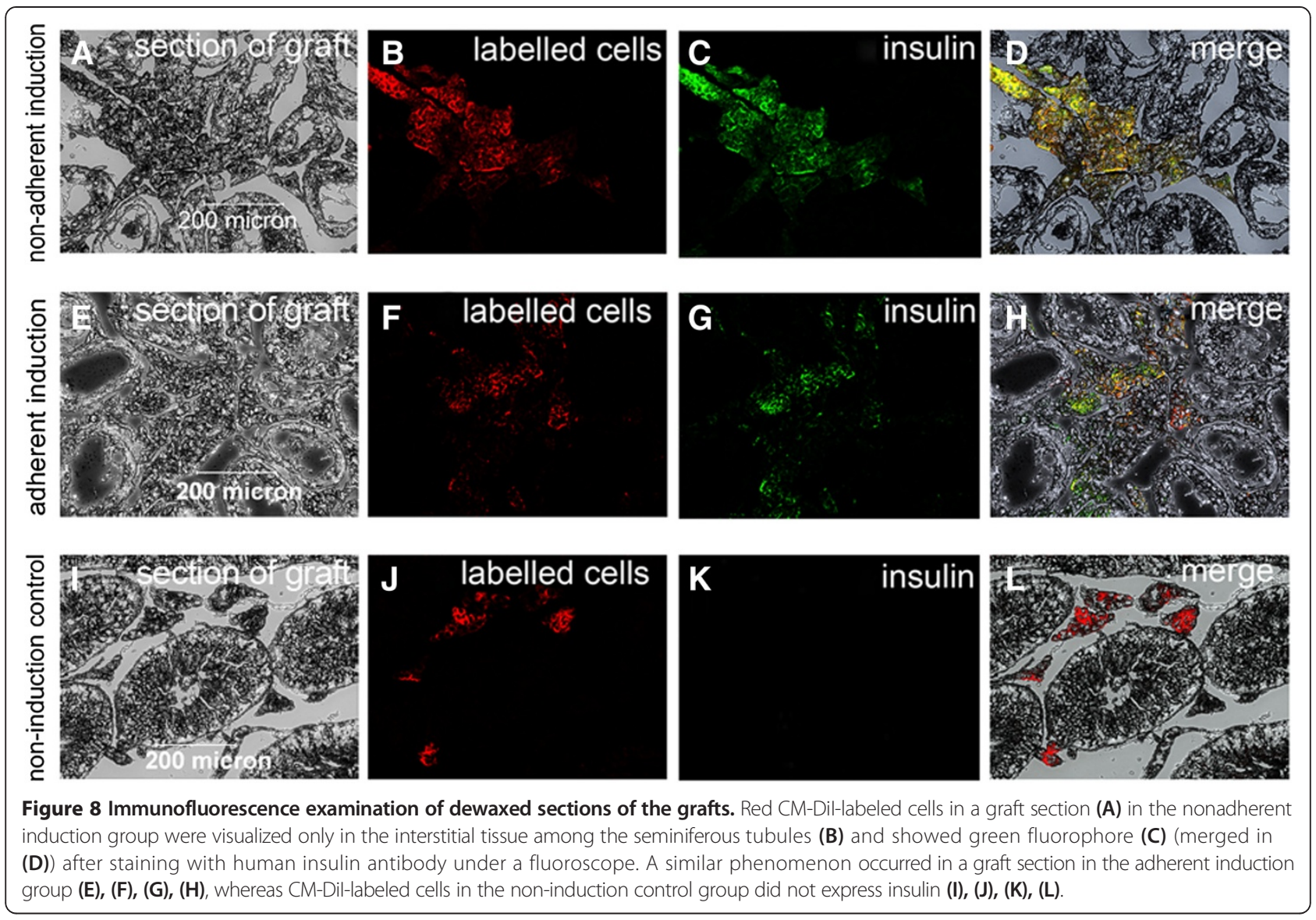

IPCs reported by $\mathrm{Wu}$ and colleagues [6]. These results indicate that nonadherent induction in noncoated plastic dishes can greatly promote BMSCs to form pancreatic islet-like cell clusters, thereby improving the differentiation rate of BMSCs towards IPCs.

In comparison with the fetal pancreatic islets, the isletlike cell clusters from hfBMSCs expressed more Ngn3 and Pax4, the markers of early stage beta-cell development, and secreted relatively lower insulin, glucagon, SST and PP (all $P<0.01, n=10$ ), indicating that their differentiation was not full in vitro.

\section{Effects of islet-like cell clusters on mouse diabetic} treatment

Although some attempts have been made to treat diabetes in an animal model with induced BMSCs in adherence, the results are not ideal. $\mathrm{Wu}$ and colleagues reported that the glucose levels of STZ-induced diabetic rats began decreasing at day 6 after the allograft with $5 \times 10^{6}$ induced rat BMSCs in adherence, and remained below $15 \mathrm{mmol} / \mathrm{l}$ from day 12 to day 16 post transplantation but elevated again after day 20 [6]. The research by Hisanaga and colleagues showed that the plasma glucose level of STZ-induced diabetic mice markedly fell after the allograft with $5 \times 10^{7}$ induced mouse BMSCs in adherence and the effect continued for at least 4 weeks [7]. Xie and colleagues ameliorated the diabetic conditions of STZ-treated mice by the transplantation of IPCs derived from BMSCs [9]. In this study, the hyperglycemia of diabetic nude mice was normalized by transplanting 600 pancreatic islet-like cell clusters (about $7.2 \times 10^{5}$ cells) from hfBMSCs. The blood glucose levels of three mice rose again after removal of the grafts while seven mice without removal of the graft maintained normal blood glucose levels for at least 80 days (Figure 7A), indicating that the transplanted cells were responsible for the cure of hyperglycemia. This observation was further confirmed by colabeling of CM-DiI and immunofluorescent antibodies against human insulin in the grafts, which demonstrated that the transplanted cells produced functional human insulin in vivo (Figure 8).

In addition, in this study the islet-like cell clusters were transplanted in the testes of model animals because not only there is a strong blood circulation in the testis but also operation of cell transplantation and withdrawal of the graft aimed at the testis is easier than that aimed at other organs, such as a renal subcapsular graft. The transplanted islet-like cell clusters normalized the blood glucose levels of diabetic model mice 12 days after transplantation (Figure 7A), implying that 
they might go through a process of adaptation, proliferation, maturation and gradual functioning in vivo.

\section{BMSCs from human first-trimester abortus}

We are not advocating carrying out abortions for the single purpose of obtaining human fetal BMSCs, but a human abortus is a source of obtaining a variety of fetal stem cells, especially in some countries with family planning policy or birth-control policy. Certainly, such an approach may be controversial in some other countries. The properties of hfBMSCs range between those of embryonic stem cells and adult stem cells, but hfBMSCs form no tumors in mice [29] whereas embryonic stem cells induced towards IPCs still form tumors in mice $[30,31]$. Thus hfBMSCs are an ideal type of seed cell for research on human tissue engineering and regeneration medicine.

\section{Conclusions}

This study demonstrates that nonadherent induction can greatly promote BMSCs to form pancreatic islet-like cell clusters, thereby improving the differentiation efficiency of BMSCs towards IPCs.

\section{Abbreviations \\ BMSC: bone marrow mesenchymal stem cell; BSA: bovine serum albumin; DMEM: Dulbecco's modified Eagle's medium; EGF: epidermal growth factor; hfBMSC: bone marrow mesenchymal stem cell of human first-trimester abortus; IPC: insulin-producing cell; PBS: phosphate-buffered saline; STZ: streptozocin.}

\section{Competing interests}

The authors declare that they have no competing interests.

\section{Authors' contributions}

YZ participated in the design of the study, carried out the whole experiment, performed the statistical analysis of data, drafted the manuscript and approved the final manuscript. ZD participated in the design, coordination and the revision of the manuscript, and approved the final manuscript.

\section{Acknowledgments}

The authors thank support from the National Natural Science Foundation of China (31372490) and all members in the Shaanxi Branch of National Stem Cell Engineering and Technology Centre for their invaluable help, especially Dr Yuankui Chu. They also thank the approval of the Ethics Committee of Northwest A \& F University and the Institutional Animal Care and Use Committee of Northwest A \& F University.

\section{Received: 22 January 2014 Revised: 22 January 2014}

Accepted: 19 May 2014 Published: 8 May 2014

\section{References}

1. Aanstoot HJ, Anderson BJ, Daneman D, Danne T, Donaghue K, Kaufman F, Rea RR, Uchigata Y: The global burden of youth diabetes: perspectives and potential. Pediatr Diabetes 2007, 8:1-44

2. Srinivasan P, Huang GC, Amiel SA, Heaton ND: Islet cell transplantation. Postgrad Med J 2007, 83:224-229.

3. Berney T, Ferrari-Lacraz S, Buhler L, Oberholzer J, Marangon N, Philippe J, Villard J, Morel P: Long-term insulin-independence after allogeneic islet transplantation for type 1 diabetes: over the 10-year mark. Am J Transplant 2009, 9:419-423.

4. Tang D-Q, Cao L-Z, Burkhardt BR, Burkhardt, Chang-Qi X, Litherland SA, Atkinson MA, Li-Jun Y: In vivo and in vitro characterization of insulin- producing cells obtained from murine bone marrow. Diabetes 2004, 53:1721-1732.

5. Oh SH, Muzzonigro TM, Bae SH, LaPlante JM, Hatch HM, Petersen BEA: Dult bone marrow-derived cells trans-differentiating into insulin-producing cells for the treatment of type I diabetes. Lab Invest 2004, 84:607-617.

6. Wu XH, Liu CP, Xu KF, Mao XD, Zhu J, Jiang JJ, Cui D, Zhang M, Xu Y, Liu C: Reversal of hyperglycemia in diabetic rats by portal vein transplantation of islet-like cells generated from bone marrow mesenchymal stem cells. World J Gastroenterol 2007, 13:3342-3349.

7. Hisanaga E, Park KY, Yamada S, Hashimoto H, Takeuchi T, Mori M, Seno M, Umezawa K, Takei I, Kojima I: A simple method to induce differentiation of murine bone marrow mesenchymal cells to insulin-producing cells using conophylline and betacellulin-delta4. Endocr J 2008, 55:535-543.

8. Chang CF, Hsu KH, Chiou SH, Ho LL, Fu YS, Hung SC: Fibronectin and pellet non-adherent culture promote differentiation of human mesenchymal stem cells into insulin producing cells. J Biomed Mater Res A 2008, 86:1097-1105

9. Xie Q-P, Huang H, Bin X, Dong X, Gao SL, Zhang B, Wu YL: Human bone marrow mesenchymal stem cells differentiate into insulin-producing cells upon microenvironmental manipulation in vitro. Differentiation 2009, 77:483-491.

10. Neshati Z, Matin MM, Bahrami AR, Moghimi A: Differentiation of mesenchymal stem cells to insulin-producing cells and their impact on type 1 diabetic rats. J Physiol Biochem 2010, 66:181-187.

11. Gabr MM, Zakaria MM, Refaie AF, Ismail, Amani M, Abou E-M, Mona A, Ashamallah, Sylvia A, Khater, Sherry M, El-Halawani, Sawsan M, Ibrahim, Rana Y, Uin, Gan S, Kloc, Malgorzata C, Roy Y, Ghoneim, Mohamed A: Insulin-producing cells from adult human bone marrow mesenchymal stem cells control streptozotocin-induced diabetes in nude mice. Cell Transplant 2013, 22:133-145.

12. Vija L, Farge D, Gautier JF, Vexiaub P, Dumitrached C, Bourgaritc A, Verrecchiaa F, Larghero J: Mesenchymal stem cells: stem cell therapy perspectives for type 1 diabetes. Diabetes Metab 2009, 35:85-93.

13. Le Blanc K, Ringden O: Immunomodulation by mesenchymal stem cells and clinical experience. J Intern Med 2007, 262:509-525.

14. Ozaki K, Sato K, Oh I, Meguro A, Tatara R, Muroi K, Ozawa K: Mechanisms of immunomodulation by mesenchymal stem cells. Int J Hematol 2007, 86:5-7.

15. Abdi R, Fiorina P, Adra CN, Adra, Mark A, Mohamed H, Sayegh: Immunomodulation by mesenchymal stem cells: a potential therapeutic strategy for type 1 diabetes. Diabetes 2008, 57:1759-1767.

16. Madec AM, Mallone R, Afonso G, Abou Mrad E, Mesnier A, Eljaafari A, Thivolet C: Mesenchymal stem cells protect NOD mice from diabetes by inducing regulatory T cells. Diabetologia 2009, 52:1391-1399.

17. Fiorina P, Jurewicz M, Augello A, Vergani A, Dada S, La Rosa S, Selig M, Godwin J, Law K, Placidi C, Neal Smith R, Carlo C, Scott R, Chaker N, Adra, Mark A, Mohamed H, Sayegh, Reza A: Immunomodulatory function of bone marrow-derived mesenchymal stem cells in experimental autoimmune type 1 diabetes. I Immunol 2009, 183:993-1004.

18. Brusko TM: Mesenchymal stem cells: a potential border patrol for transplanted islets? Diabetes 2009, 58:1728-1729.

19. Li FR, Wang XG, Deng CY, Qi H, Ren LL, Zhou HX: Immune modulation of co-transplantation mesenchymal stem cells with islet on $\mathrm{T}$ and dendritic cells. Clin Exp Immunol 2010, 161:357-363.

20. Lim J-H, Kim J-S, Yoon I-H, Shin J-S, Nam H-Y, Yang S-H, Kim S-J, Park C-G: Immunomodulation of delayed-type hypersensitivity responses by mesenchymal stem cells is associated with bystander T cell apoptosis in the draining lymph node. J Immunol 2010, 185:4022-4029.

21. Volarevic V, Al-Qahtani A, Arsenijevic N, Sladjana P, Lukic ML: Interleukin-1 receptor antagonist (IL-1Ra) and IL-1 Ra producing mesenchymal stem cells as modulators of diabetogenesis. Autoimmunity 2010, 43:255-263.

22. Kover K, Moore WV: Development of a method for isolation of islets from human fetal pancreas. Diabetes 1989, 38:917-924.

23. Soria B, Roche E, Berna G, Leon-Quinto T, Reig JA, Martin F: Insulin secreting cells derived from embryonic stem cells normalize glycemia in streptozotocin-induced diabetic mice. Diabetes 2000, 49:157-162.

24. Bernard AB, Chien-Chi L, Kristi S: A microwell cell culture platform for the aggregation of pancreatic $\beta$-cells. Tissue Eng C 2012, 18:583-592.

25. Kedees MH, Guz Y, Vuguin PM, Vargas C, Cui L, Steiner DF, Charron MJ, Teitelman G: Nestin expression in pancreatic endocrine and exocrine cells of mice lacking glucagon signaling. Dev Dyn 2007, 236:1126-1133. 
26. Bernardo AS, Barrow J, Hay CW, Kenneth MC, Kindb AJ, Schniekeb AE, Alan C, Hartb AW, Kevin D: Presence of endocrine and exocrine markers in EGFP-positive cells from the developing pancreas of a nestin/EGFP mouse. Mol Cell Endocrinol 2006, 253:14-21.

27. Jafary H, Larijani B, Farrokhi A, Pirouza M, Mollamohammadia S, Baharvand H: Differential effect of activin on mouse embryonic stem cell differentiation in insulin-secreting cells under nestin-positive selection and spontaneous differentiation protocols. Cell Biol Int 2008, 32:278-286.

28. Kim S-Y, Lee S, Hong S-W, Min B-H, Lee K-U, Bendayan M, Park I-S: Nestin action during insulin-secreting cells differentiation. J Histochem Cytochem 2010, 58:567-576.

29. Yihua Z, Zhongying D, Wenzheng S, Chunrong Y, Zhimin G: Isolation and culture of bone marrow mesenchymal stem cells from human fetus and their properties. Chin J Agric Biotechnol 2008, 5:237-244.

30. Fujikawa T, Seh-Hoon O, Pi L, Hatch HM, Tom S, Petersen BE: Teratoma formation leads to failure of treatment for type I diabetes using embryonic stem cell-derived insulin-producing cells. Am J Pathol 2005, 166:1781-1791.

31. Raikwar SP, Zavazava N: PDX1-engineered embryonic stem cell-derived insulin producing cells regulate hyperglycemia in diabetic mice. Transplant Res 2012, 1:19-29.

doi:10.1186/scrt455

Cite this article as: Zhang and Dou: Under a nonadherent state, bone marrow mesenchymal stem cells can be efficiently induced into

functional islet-like cell clusters to normalize hyperglycemia in mice: a control study. Stem Cell Research \& Therapy 2014 5:66.

\section{Submit your next manuscript to BioMed Central and take full advantage of:}

- Convenient online submission

- Thorough peer review

- No space constraints or color figure charges

- Immediate publication on acceptance

- Inclusion in PubMed, CAS, Scopus and Google Scholar

- Research which is freely available for redistribution 